\title{
Anti-Inflammatory Activity of Bullfrog Oil Polymeric Nanocapsules: From the Design to Preclinical Trials
}

\author{
Lucas Amaral-Machado (D) \\ Wógenes $\mathrm{N}$ Oliveira \\ Manoela Torres-Rêgo (D) ${ }^{2}$ \\ Allanny A Furtado ${ }^{3}$ \\ Éverton N Alencar' \\ Matheus F Fernandes-Pedrosa ${ }^{3}$ \\ Hugo AO Rocha $\mathbb{D}^{1}$ \\ Eryvaldo Sócrates Tabosa \\ Egito (iD) ${ }^{1,3}$ \\ 'Graduate Program in Health Sciences, \\ Federal University of Rio Grande do \\ Norte, Natal, Rio Grande do Norte, \\ Brazil; ${ }^{2}$ Chemistry Institute, Federal \\ University of Rio Grande do Norte, \\ Natal, Rio Grande do Norte, Brazil; \\ ${ }^{3}$ Graduate Program of Pharmaceutical \\ Sciences, Federal University of Rio \\ Grande do Norte, Natal, Rio Grande do \\ Norte, Brazil
}

Background: Although bullfrog oil (BFO) exerts anti-inflammatory effects, it has undesirable properties limiting its use.

Methodology: BFO nanocapsules (BFONc) were produced through nanoprecipitation, and their physicochemical and morphological properties were characterized. To evaluate the biocompatibility of the formulation, a mitochondrial activity evaluation assay was conducted, and cell uptake was assessed. The in vitro anti-inflammatory activity was evaluated by measuring reactive oxygen species (ROS), nitric oxide (NO), type-6 interleukin (IL-6), and tumor necrosis factor (TNF) levels. The in vivo anti-inflammatory effect was assessed by quantifying myeloperoxidase (MPO) levels using the carrageenan-induced paw edema model. Results: BFONc showed a particle size of $233 \pm 22 \mathrm{~nm}$, a polydispersity index of $0.17 \pm$ 0.03 , and a zeta potential of $-34 \pm 2.6 \mathrm{mV}$. BFONc revealed remarkable biocompatibility and did not induce changes in cell morphology. Furthermore, BFONc decreased ROS levels by $81 \pm 4 \%$; however, NO level increased by $72 \pm 18 \%$. TNF and IL-6 levels were reduced by approximately $10 \%$ and $90 \%$, respectively. Significant in vivo anti-inflammatory activity was observed compared to dexamethasone. MPO levels were reduced up to $2 \mathrm{MPOs} / \mathrm{mg}$.

Conclusion: Taken together, the results pointed out the remarkable biocompatibility and anti-inflammatory effects of BFONc.

Keywords: polyunsaturated fatty acids, bullfrog oil, nanocapsules, anti-inflammatory activity

\section{Introduction}

Polyunsaturated fatty acids (PUFAs), a lipid group that contains a carbon chain whose chemical structure is composed of at least 18 carbon atoms, are represented by omega-3 ( $\alpha$-linolenic, eicosapentaenoic (EPA), and docosahexaenoic acids (DHA)) and omega-6 fatty acids series (linoleic and arachidonic acids (ARA)). They have been widely used in traditional medicine because of their therapeutic potential against several diseases, ${ }^{1,2}$ especially inflammatory disorders. $^{1,3-5}$

Therefore, several natural products have been used as PUFA sources, including marine animal byproducts. ${ }^{6,7}$ In this context, recent studies have described new PUFA sources with potential biological effects and bullfrog oil (BFO), in particular, has drawn some attention. ${ }^{8}$ This oil is a byproduct obtained from hot extraction of the adipose tissue, which is discarded during Rana catesbeiana Shaw meat processing, an anuran meat marketed worldwide. ${ }^{9,10}$

As a natural oil, BFO has been used as an alternative and complementary medicine owing to its anti-inflammatory potential, which is due to its high
Correspondence: Eryvaldo Sócrates Tabosa Egito

Federal University of Rio Grande do

Norte, Rua Jaguarari, 4985 - Apt. I603D

- 59054-500, Natal, Rio Grande do

Norte, Brazil

Tel +55-84-994-31-88-16

Fax +55-84-3342-9817;

$+55-84-3342-9817-9808$

Email socratesegito@gmail.com 
omega-3 and omega- 6 content (up to $26 \%$ ) as described by Amaral-Machado et al and Rutckeviski et al. ${ }^{9,11}$ Additionally, studies have found that oleic acid, a monounsaturated fatty acid described as the biosynthetic precursor of PUFAs, is the major compound (29.9\%) in BFO. This fatty acid paves the way for PUFA synthesis; oleic acid desaturation occurs, linoleic acid is formed and can be further desaturated into $\gamma$-linolenic acid (omega-6) or $\alpha$-linolenic acid (omega-3). Because these compounds are precursors of prostanoids and leukotrienes, which modulate the inflammatory process, the therapeutic potential of BFO against inflammatory disorders has been demonstrated. $^{1,5,9}$

In this regard, studies evaluating BFO antiinflammatory activity have revealed its ability to decrease intracellular nitric oxide, type-6 interleukin (IL-6), and tumor necrosis factor (TNF) levels in lipopolysaccharide (LPS)-stimulated macrophages (Raw 264.7 cells). Moreover, in vivo studies have indicated that BFO decreased tissue inflammation in Wistar rats and Swiss mice as expressively as indomethacin, highlighting the anti-inflammatory potential of this oil., ${ }^{8,12}$ Although they provided useful knowledge for further research, these studies focused only on the activity of BFO in natura. It is well known that this oil presents challenging physicochemical and organoleptic characteristics, such as unfavorable smell, flavor, and spreadability, which contribute negatively to therapeutic compliance. ${ }^{9,11,13}$

In this context, researchers have developed technological approaches to overcome the undesirable characteristics of BFO. ${ }^{9,13,14}$ Davim et al evaluated the anti-inflammatory activity of BFO in natura and a BFO-based microemulsion. This emulsified system theoretically could overcome the disadvantages of BFO in natura. ${ }^{8}$ This microemulsion was composed of $90 \%$ of BFO, suggesting an oily external phase. However, the authors did not characterize the emulsified nanostructured system. ${ }^{8}$ Moreover, based on the microemulsion composition $(90 \% \mathrm{BFO}, 5 \%$ soy lecithin, and $5 \%$ ethanol at 70\%), the reported BFO-based microemulsion was unable to mask the undesirable physicochemical and organoleptic characteristics of BFO.

To overcome such drawbacks, there is a need to develop a suitable therapeutic system that can mask the organoleptic characteristics of BFO, improve its physicochemical properties and therapeutic effects, and enable its release. Based on this rationale, nanocapsules stand out as a promising alternative. These polymeric vesicular nanostructured systems are typically composed of a liquid lipophilic core surrounded by a polymeric shell known for its high encapsulation efficiency in lipophilic drugs, small molecules, and oily compounds, including fatty acids. ${ }^{15-17}$ In addition to natural oils, utilizing biocompatible polymers allows the production of biocompatible systems, which will contribute to the therapeutic use of nanocapsules owing to their low toxic effects. ${ }^{18}$

Therefore, this work aimed to develop suitable BFObased nanocapsules for oral administration and evaluate their ability to enhance or maintain the anti-inflammatory activity of BFO.

\section{Materials and Methods}

Griess reagent, lipopolysaccharide (LPS), MTT (3-(4,5-Dimethylthiazol-2-yl)-2,5-Diphenyltetrazolium

Bromide) reagent, 2',7'-dichlorofluorescein diacetate (DCFH-DA), Nile red, Hoechst solution, phosphate buffer standard (PBS), polycaprolactone (PCL; molecular weight: $80,000)$, saponin, dexamethasone, mineral oil, hexadecyltrimethylammonium bromide buffer, potassium phosphate, hydrogen peroxide, o-dianisidine, $\operatorname{Span}{ }^{\circledR} 60$ (sorbitan monooleate 60), and Tween ${ }^{\circledR} 80$ (polysorbate 80 ) were obtained from Sigma-Aldrich, Inc. (St. Louis, MO, EUA). Analyticalgrade acetone, dimethyl sulfoxide (DMSO), methanol, and ethanol were purchased from Vetec (Rio de Janeiro, RJ, Brazil). Dulbecco's Modified Eagle's Medium (DMEM) and fetal bovine serum (FBS) were obtained from Cultilab (São Paulo, SP, Brazil). The murine macrophage cell line Raw 264.7 (ATCC ${ }^{\circledR}$ TIB-71 ${ }^{\mathrm{TM}}$ ) and bullfrog (Rana catesbeiana Shaw) adipose tissue were donated by the Laboratory of Biopolymers, Federal University of Rio Grande do Norte (UFRN) (Natal, RN, Brazil) and Asmarana Produtos Naturais (Natal, RN, Brazil), respectively.

\section{Development of Bullfrog Oil-Based Nanocapsules}

Bullfrog oil nanocapsules (BFONc) were developed according to the interfacial polymer deposition technique following the solvent displacement (nanoprecipitation) method described by Fessi et al. ${ }^{19}$ Accordingly, two phases (aqueous and organic) were prepared separately. The aqueous phase, composed of Tween ${ }^{\circledR} 80(77 \mathrm{mg})$ and purified water $(53 \mathrm{~mL})$, and the organic phase, composed of acetone $(27 \mathrm{~mL}), \mathrm{BFO}$ (160 mg), PCL (100 mg), and Span ${ }^{\circledR} 60$ (38 mg), were mixed separately under moderate magnetic stirring $(200 \mathrm{rpm})$ at $40{ }^{\circ} \mathrm{C}$ until the compounds were completely dissolved. Next, the organic phase was continuously poured into the 
aqueous phase, followed by homogenization for $10 \mathrm{~min}$ minimum. The organic solvent was eliminated at $40{ }^{\circ} \mathrm{C}$ by rotary evaporation (Rotary Evaporator R3; BÜCHI Labortechnik AG, Flawil, St. Gallen, CHE). Finally, the remaining volume was adjusted to $10 \mathrm{~mL}$ using purified water.

\section{Physicochemical Characterization - Determination of Size Distribution, Zeta Potential, and Stability Evaluation of the Nanocapsules}

Particle size distribution was determined by dynamic light scattering (DLS). The samples, diluted at 1:100 (v/v) in purified water, were previously prepared and analyzed using a ZetaSize NanoZS instrument (Malvern Instruments, Malvern, UK) pre-calibrated at $25^{\circ} \mathrm{C}$ and an angle fixed at $173^{\circ}$ for the particle size and polydispersity index (PdI) readings. Additionally, the electrophoretic mobility of BFONc was measured to assess the zeta potential. For this purpose, the nanocapsules were diluted $\left(1: 500_{(\mathrm{v} / \mathrm{v})}\right)$ in a sodium chloride solution $(0.1 \mathrm{mM})$ to maintain the ionic strength and then analyzed at $25{ }^{\circ} \mathrm{C}$. Both size distribution and zeta potential analyses were performed in triplicate. Finally, the BFONc was stored at room temperature $\left(25 \pm 2{ }^{\circ} \mathrm{C}\right)$ and humidity rate of $75 \%$, continuously monitored by a thermo-hygrometer and then evaluated for physicochemical stability over 30 days according to the aforementioned parameters.

\section{Morphological Characterization - Transmission Electron Microscopy (TEM) of the Nanocapsules}

BFONc morphology was evaluated using a JEOL 1400120 $\mathrm{kV}$ microscope (Peabody, MA, USA). Accordingly, $5 \mu \mathrm{L}$ of nanocapsules, previously diluted in ultra-purified water $(1: 500(\mathrm{v} / \mathrm{v}))$, was placed in a carbon film-covered grid (400 mesh) for $1 \mathrm{~min}$, and the excess sample was removed using an absorbent paper. Subsequently, the contrast agent (phosphotungstic acid at $2 \%$ ) was added and maintained 30 s. Finally, an Orius camera (Gatan, Pleasanton, CA, USA) was used to obtain the micrographs.

\section{In vitro Cytotoxicity/Biocompatibility Evaluation of the Nanocapsules Mitochondrial Activity Evaluation}

The MTT assay was performed to evaluate BFONc cytotoxicity against a murine macrophage cell line
(Raw 264.7). The cells were placed in 96-well plates $\left(5 \times 10^{4}\right.$ cells/well) and incubated at $37 \pm 2{ }^{\circ} \mathrm{C}$ in a $5 \%$ $\mathrm{CO}_{2}$ atmosphere for $24 \mathrm{~h}$ in DMEM supplemented with $10 \%$ of FBS. The BFONc was then diluted in purified water to obtain a stock solution at $2 \mathrm{mg} \cdot \mathrm{mL}^{-1}$ of BFO concentration. A solution of $2 \mathrm{mg} \cdot \mathrm{mL}^{-1}$ of free BFO, dispersed in DMSO aqueous solution (1\% (v/v)), was also prepared for data comparison. Subsequently, these solutions were diluted in DMEM to reach final BFO concentrations $\left(50,100\right.$, and $\left.500 \mu \mathrm{g} . \mathrm{mL}^{-1}\right)$, which were then added to the cells, followed by incubation for 24 and $48 \mathrm{~h}$. Finally, after each incubation period, the medium containing the samples was removed, and $100 \mu \mathrm{L}$ of DMEM containing MTT reagent $\left(1 \mathrm{mg} \cdot \mathrm{mL}^{-1}\right)$ was added, followed by $4 \mathrm{~h}$ of incubation. The formazan crystals formed via MTT salt reduction were dissolved in analytical grade ethanol $(100 \mu \mathrm{L})$. The absorbance was read using an Elisa Multiskan Ascent Microplate Reader (Thermo Labsystems, Franklin, MA, USA) set at $570 \mathrm{~nm}$. Untreated cells were used as a negative control, representing $100 \%$ mitochondrial activity and assuming $100 \%$ cell viability. The dispersion of the nanocapsules components of the formulation (except the BFO) was also tested to evaluate their toxicity. Cell viability was determined by the relative absorbance between the untreated cells and the samples. This assay was performed in triplicate.

\section{Cells Morphological Evaluation - Cell Uptake of Bullfrog Oil Nanocapsules}

Fluorescence microscopy was used to observe the cell uptake of free BFO and BFONc. For this purpose, RAW 264.7 cells were placed in 6 -well plates $\left(5 \times 10^{5}\right.$ cells/ well) for $24 \mathrm{~h}$ in DMEM supplemented with 10\% FBS and subsequently treated with free BFO and BFONc at $100 \mu \mathrm{g} . \mathrm{mL}^{-1}$ for 6,12 , and $24 \mathrm{~h}$. The samples were previously stained with Nile red fluorescent dye (directly solubilized in bullfrog oil) at $0.1 \%(\mathrm{w} / \mathrm{w})$ (relative to oil content). After treatment, the cells were washed with cold PBS, fixed with methanol (15 min), and permeabilized with saponin $0.05 \%$ (w/v) aqueous solution (15 min). Moreover, the cell nuclei were stained with $200 \mu \mathrm{L}$ of Hoechst staining solution at $0.1 \mu \mathrm{g} \cdot \mathrm{mL}^{-1}$ (10 $\left.\mathrm{min}\right)$. After that, the staining solution was removed, and $200 \mu \mathrm{L}$ of cold PBS was added to the wells. The cells were visualized using a fluorescence microscope (Nikon Eclipse 600 Fluorescence, Tokyo, Japan). 


\section{In vitro Anti-Inflammatory Activity Evaluation \\ Measurement of Intracellular Reactive Oxygen Species (ROS) Levels}

Free BFO and BFONc were tested for their ability to prevent intracellular ROS generation. RAW 264.7 cells were placed into 24 -well plates (cell density: $3 \times 10^{5}$ cells/ well), incubated for $24 \mathrm{~h}$ with $10 \%$ FBS-supplemented DMEM, and then stimulated with LPS for $12 \mathrm{~h}$. After that, the medium was replaced with the treatment dispersion (free BFO and BFONc) at BFO concentrations of 50, 100 , and $500 \mu \mathrm{g} \cdot \mathrm{mL}^{-1}$ in DMEM, and the treatment was maintained for 24 and $48 \mathrm{~h}$. Subsequently, the treatment dispersion was removed, and DCFH-DA $10 \mu \mathrm{M}$ solution in $1 \%$ FBS-supplemented DMEM medium was added, followed by incubation for $2 \mathrm{~h}$ at $37 \pm 2{ }^{\circ} \mathrm{C}$ and $5 \%$ $\mathrm{CO}_{2}$. Finally, the cells were washed with cold PBS, detached with trypsin, centrifuged at $1840 \times \mathrm{g}$ for $6 \mathrm{~min}$ at $4{ }^{\circ} \mathrm{C}$, and resuspended in $200 \mu \mathrm{L}$ of PBS. Intracellular ROS levels were determined by flow cytometry (FACSCanto II; BD Biosciences, OR, USA), with 20,000 events acquired. Untreated cells were used as negative controls. The FlowJo software version X10.0.7 (Tree Star, Inc., Ashland, OR, USA) was used for data analysis.

\section{Determination of the Nitric Oxide (NO) Levels from Macrophages}

The Griess reaction technique was used to determine the level of NO released by RAW 264.7 macrophages after LPS $2 \mu \mathrm{g} \cdot \mathrm{mL}^{-1}$ stimulation for $12 \mathrm{~h}$. Briefly, the cells were placed in 24-well plates $\left(3 \times 10^{5}\right.$ cells/well $)$ using DMEM supplemented with $10 \% \mathrm{FBS}$ and incubated at $37 \pm 2{ }^{\circ} \mathrm{C}$ in a $5 \% \mathrm{CO}_{2}$ atmosphere for $24 \mathrm{~h}$. Next, the cells were treated with LPS (at the aforementioned concentration and time) to stimulate NO production, as described previously. The supernatant $(100 \mu \mathrm{L})$ was incubated with Griess reagent $(100 \mu \mathrm{L})$ for $10 \mathrm{~min}$ at room temperature $\left(25 \pm 2{ }^{\circ} \mathrm{C}\right)$, and the absorbance was subsequently measured by an Elisa Multiskan Ascent Microplate Reader (Thermo Labsystems, Franklin, MA, USA) set at 540 $\mathrm{nm}$. Untreated cells were used as negative controls. The assay was performed in duplicate.

In vitro Evaluation of Anti-Inflammatory Activity of Bullfrog Oil Nanocapsules: IL-6 and TNF Dosages To evaluate the IL-6 and TNF cytokine levels, RAW 264.7 macrophage cells were cultivated as described in the intracellular ROS level evaluation section. The cells were treated with free $\mathrm{BFO}$ and $\mathrm{BFONc}$ at 50,100 , and 500 $\mu \mathrm{g} . \mathrm{mL}^{-1}$ for $48 \mathrm{~h}$. Subsequently, cytokine levels were determined using a Cytometric Bead Array (CBA) Mouse Th1/Th2/Th17 Cytokine Kit (BD Biosciences, San Diego, CA, USA). Briefly, $50 \mu \mathrm{L}$ of the supernatant, kit capture beads, and phytoeretin antibody were incubated in the dark for $2 \mathrm{~h}$. Next, $1 \mathrm{~mL}$ of wash buffer was added, followed by centrifugation at $200 \times \mathrm{g}$ for $10 \mathrm{~min}$. Finally, the resulting pellet was resuspended in $200 \mu \mathrm{L}$ of wash buffer, and IL-6 and TNF levels were measured using a flow cytometer (FACSCANTO II; BD Bioscience, Franklin Lakes, NJ, USA). Untreated cells were used as negative controls. The assay was performed in duplicate.

\section{In vivo Anti-Inflammatory Effect Evaluation}

Ethical Protocols and Animal Care for Preclinical Trials

Male and female BALB/c mice (25-35 g, aged 5-6 weeks) were kept at a temperature of $22 \pm 2{ }^{\circ} \mathrm{C}$ with a 12 -h light/dark cycle at the Animal Facility of the Sciences Center Health, Federal University of Rio Grande do Norte (UFRN). Each group consisted of six animals $(n=6)$. After the experiments, the mice were euthanized via an intraperitoneal injection of xylazine $(30 \mathrm{mg} / \mathrm{kg}$ ) and ketamine $(300 \mathrm{mg} / \mathrm{kg})$. The Animal Experimentation Ethical Committee approved the experimental protocol of the UFRN ( $\left.\mathrm{N}^{\circ} 184.040 / 2019\right)$, and the experiment was conducted according to the National Guidelines of Ethical Principles in Animal Research adopted by the Brazilian Society of Animal Sciences and the National Brazilian Legislation $n^{\circ}$ 11.794/08.

\section{Anti-Edematogenic Effect Evaluation: Carrageenan-Induced Paw Edema Model}

The in vivo anti-edematogenic activity of $\mathrm{BFO}$ and BFONc was examined via the carrageenan-induced paw edema model according to a method described by Winter, ${ }^{20}$ with modifications. BFO and BFONc were diluted in inert oil (mineral oil) and water to reach the tested concentrations, respectively. The mice were pretreated via intragastric gavage with $300 \mu \mathrm{L}$ of saline (negative control), dexamethasone $(2 \mathrm{mg} / \mathrm{kg}$ ) (positive control), BFO $(50,100$, or $500 \mathrm{mg} /$ $\mathrm{kg})$, and BFONc $(50,100$, or $500 \mathrm{mg} / \mathrm{kg}$ oil concentration). After $1 \mathrm{~h}$, the animals received an intraplantar injection of 50 $\mu \mathrm{L}$ of $1 \% \lambda$-carrageenan $(500 \mu \mathrm{g} / \mathrm{paw}$; Sigma-Aldrich, St. Louis, Missouri, USA) or saline solution (sham group). After carrageenan administration, the paws were measured using a digital caliper at 1,2,3, and $4 \mathrm{~h}$. Paw edema was 
expressed in millimeters (mm) and calculated as the percentage of edema. The areas under the time-course curves $\left(\mathrm{AUC}_{0-4 \mathrm{~h}}\right)$ were also determined using the trapezoidal rule.

\section{Quantification of Myeloperoxidase (MPO) Levels}

Following the anti-edematogenic activity assay, the mice with carrageenan-induced paw edema were euthanized. Their hind paws were removed to determine MPO levels, as Bradley et al and Posadas et al described. ${ }^{21,22}$ Briefly, paw skin tissues were weighed, chopped, and homogenized in $0.5 \%$ hexadecyltrimethylammonium bromide buffer ( $1 \mathrm{~mL}$ of buffer for each $50 \mathrm{mg}$ of tissue). MPO enzyme was extracted by processing the sample in an T10 Basic Ultra-turrax at $2000 \mathrm{rpm}$ (IKA, Staufen, Germany) for $30 \mathrm{~s}$ in an ice bath. Subsequently, the samples were subjected to three freeze-thaw cycles and sonicated for $30 \mathrm{~s}$ in the same ultra-turrax apparatus. Finally, the samples were centrifuged at $10,000 \times \mathrm{g}$ for $10 \mathrm{~min}$ at $4{ }^{\circ} \mathrm{C}$. Next, $20 \mathrm{~mL}$ of each supernatant was mixed with $200 \mathrm{~mL}$ of $50 \mathrm{mM}$ potassium phosphate (pH 6.0) supplemented with $0.0005 \%$ hydrogen peroxide and $0.167 \mathrm{mg} /$ $\mathrm{mL}$ o-dianisidine. MPO activity was colorimetrically quantified using an Elisa Multiskan Ascent Microplate Reader (Epoch-Biotek, Winooski, VT, USA) set at 460 $\mathrm{nm}$. The kinetic approach lasted $3 \mathrm{~min}$, with $1 \mathrm{~min}$ between each reading. One unit of MPO was defined as the equivalent to the consumption of $1 \mu \mathrm{mol}$ of hydrogen peroxide per min, considering that $1 \mu \mathrm{mol}$ of hydrogen peroxide gives a change in absorbance of $1.0 \times 10^{2}$ per min.

\section{Statistical Analyses}

The data are expressed as mean \pm standard deviation. The Student's $t$-test was used to evaluate the statistical significance between two unpaired groups based on $p$ values ( $p<$ 0.05 was considered significant). Statistical analyses were carried out by one-way analysis of variance (ANOVA) with Tukey's post-test using GraphPad Prism version 5.00 (San Diego, California, United States of America). Differences in the mean values with ${ }^{* * *} p<0.001,{ }^{* *} p<0.01$, and ${ }^{*} p<$ 0.05 were considered statistically significant.

\section{Results and Discussion Bullfrog Oil Nanocapsules - Development and Physicochemical/Morphological Characterization}

To produce a biocompatible BFO-based nanostructured system suitable to be used by oral route, nanocapsules were produced by the nanoprecipitation method, a wellestablished, easy-to-perform, and reproducible technique proposed by Fessi et al. This technique allows the loading of hydrophobic drugs or oily compounds in the cores of nanocapsules. ${ }^{15}$ In addition, PCL enables the production of a biocompatible system owing to its low toxicity, a practical reason why this polymer was approved by the Food Drug Administration (FDA) to develop therapeutic products for internal use. ${ }^{16}$ Moreover, the system was characterized by particle size distribution, zeta potential, and TEM analyses. Additionally, the system's stability was evaluated over 30 days at room temperature $\left(25 \pm 2{ }^{\circ} \mathrm{C}\right)$.

Immediately after production, the BFONc system showed particle size of $233 \pm 22 \mathrm{~nm}$ and PdI of $0.17 \pm$ 0.03 (Table 1), confirming the successful development of nanocapsules. Indeed, particle size distribution is a relevant parameter for nanoparticle pharmacokinetics and drug delivery. It affects the residence time of nanoparticles in the bloodstream, their immunogenicity, their interaction, and their internalization by cells (particle targeting), in addition to their stability in organic fluids. ${ }^{15,23}$ The obtained particle size distribution can be associated with the use of PCL, as nanoparticles based on this polymer typically exhibit a diameter size of approximately 200 $\mathrm{nm} .{ }^{24}$ This can be observed in the work of Abriata et al, who developed paclitaxel-loaded PCL nanoparticles with a particle size of approximately $190 \mathrm{~nm}$ using the same polymer and production method. ${ }^{15}$ In addition, different results can be observed in the work of Liu et al. This author used a modified PCL polymer to develop chitosancoated PCL nanoparticles intended for curcumin delivery. These nanoparticles had a particle size of approximately $360 \mathrm{~nm}$ at $\mathrm{pH} 7,{ }^{16}$ reinforcing the hypothesis regarding the influence of the polymer used on nanoparticle size.

Table I Stability Assessment via Physicochemical Characterization of Bullfrog Oil Nanocapsules Stored at Room Temperature Over 30 Days

\begin{tabular}{|l|c|c|c|}
\hline Day & $\begin{array}{c}\text { Size }(\mathbf{n m}) \\
\pm \text { SD }\end{array}$ & Pdl \pm SD & $\begin{array}{c}\text { Zeta Potential }(\mathbf{m V}) \\
\mathbf{\pm ~ S D}\end{array}$ \\
\hline 0 & $233 \pm 22$ & $0.17 \pm 0.03$ & $-34 \pm 2.6$ \\
$\mathrm{I}$ & $229 \pm 21$ & $0.17 \pm 0.02$ & $-29 \pm 3.1$ \\
5 & $234 \pm 21$ & $0.17 \pm 0.03$ & $-31 \pm 2.4$ \\
15 & $234 \pm 23$ & $0.17 \pm 0.03$ & $-27 \pm 3.7$ \\
30 & $237 \pm 22$ & $0.16 \pm 0.03$ & $-29 \pm 2.1$ \\
\hline
\end{tabular}

Abbreviations: $\mathrm{nm}$, nanometers; Pdl, polydispersity index; $\mathrm{mV}$, millivolts; SD, standard deviation. 
Furthermore, the obtained zeta potential $(-34 \pm 2.6$ $\mathrm{mV}$ ) suggests that the system presents electrostatic stability. The module's zeta potential $>25 \mathrm{mV}$ indicates that the repulsion forces are more potent than the attraction forces. These prevent the attraction forces from occurring and allow the nanoparticles to remain suspended over long periods. $^{25}$ Additionally, as zeta potential is also related to the nanoparticle surface charge (the presence of ionized groups of charged polymers/surfactants), the obtained negative values can be attributed to PCL, as nanoparticles based on this polymer show negative surface charge, ${ }^{24}$ as described by Byun et al. In contrast, $\alpha$-tocopherol-loaded PCL nanoparticles exhibit a negative zeta potential of approximately $-15 \mathrm{mV}^{26}$ Indeed, the zeta potential can be directly influenced by the polymer used to produce the carrier. Our work supports Byun et al, in which similar zeta potential results were obtained. These results also corroborate the study by Rafiei and Haddadi, who found a zeta potential of $-28 \mathrm{mV}$ for docetaxel-loaded PLGA nanoparticles. $^{27}$

TEM analyses revealed the spherical shape of BFONc, with a size distribution similar to that obtained by DLS (Figure 1 and Table 1). These results agree with those of Zanetti et al, who developed nanoparticles using PLC and nanoprecipitation as the production method. The geranyl cinnamate PCL nanoparticles produced by these authors also presented a spherical shape. ${ }^{18}$ In addition, the obtained image suggests that BFO was loaded into the nanocapsules core, as no free BFO droplets were observed on the images or appeared to be adsorbed on the nanocapsules surface.

Furthermore, the BFONc stability study revealed that the nanoparticles did not show significant changes $(p>$ $0.05)$ in particle size distribution and zeta potential following 30 days of storage at room temperature $\left(25 \pm 2{ }^{\circ} \mathrm{C}\right)$.
This study suggests no instability phenomena (aggregation) or even degradation of the nanoparticles (Table 1). Several studies have highlighted that indomethacin, cyclosporin A, and flurbiprofen-loaded PCL nanoparticles had favorable stability when stored at different temperatures $\left(4,25\right.$, or $\left.40{ }^{\circ} \mathrm{C}\right)$, showing no significant changes in nanoparticles' size, zeta potential, or $\mathrm{pH}$ after storage for up to 6 months. ${ }^{24,28-30}$

Hence, the obtained results indicated that BFONc with suitable physicochemical characteristics was successfully developed. The nanostructured system remained stable over 30 days at room temperature, suggesting its suitability as a carrier for BFO.

\section{In vitro Cytotoxicity/Biocompatibility Evaluation}

An MTT test was used to determine the biocompatibility and cytotoxicity of the nanoparticles generated. The influence of free BFO and BFONc on MTT reduction was evaluated in RAW 264.7 murine macrophage cells (Figure 2).

The MTT results showed that neither free BFO nor BFONc significantly decreased the mitochondrial activity of the cells at all tested concentrations (Figure 2). Indeed, no significant difference was observed between the treated cells and the control (untreated cells) $(p>0.05)$. Similar results were observed for the nanocapsules dispersion components (data not shown). Moreover, the mitochondrial activity remained higher than $80 \%$ at all tested times, suggesting the absence of toxicity of the tested compounds. $^{31}$ These data are in agreement to the previous findings that despite decreasing cancer cell viability (A2058 human melanoma cells and B16F10 murine melanoma cells) at similar concentrations, BFO and nanostructured systems based on this oil, such as
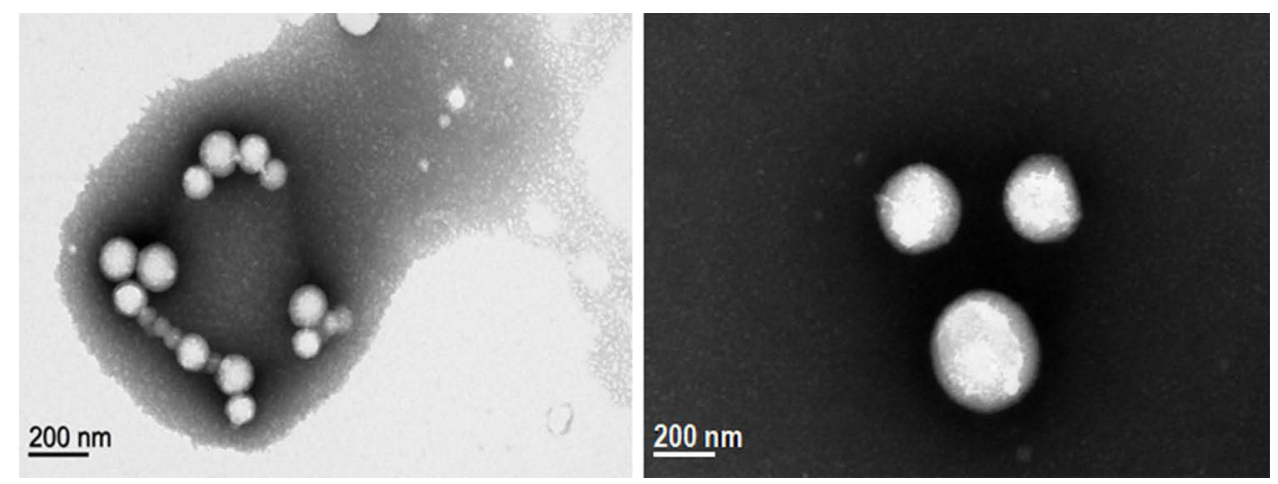

Figure I Morphological characterization of bullfrog oil-based nanocapsules by Transmission Electron Microscopy (TEM). 


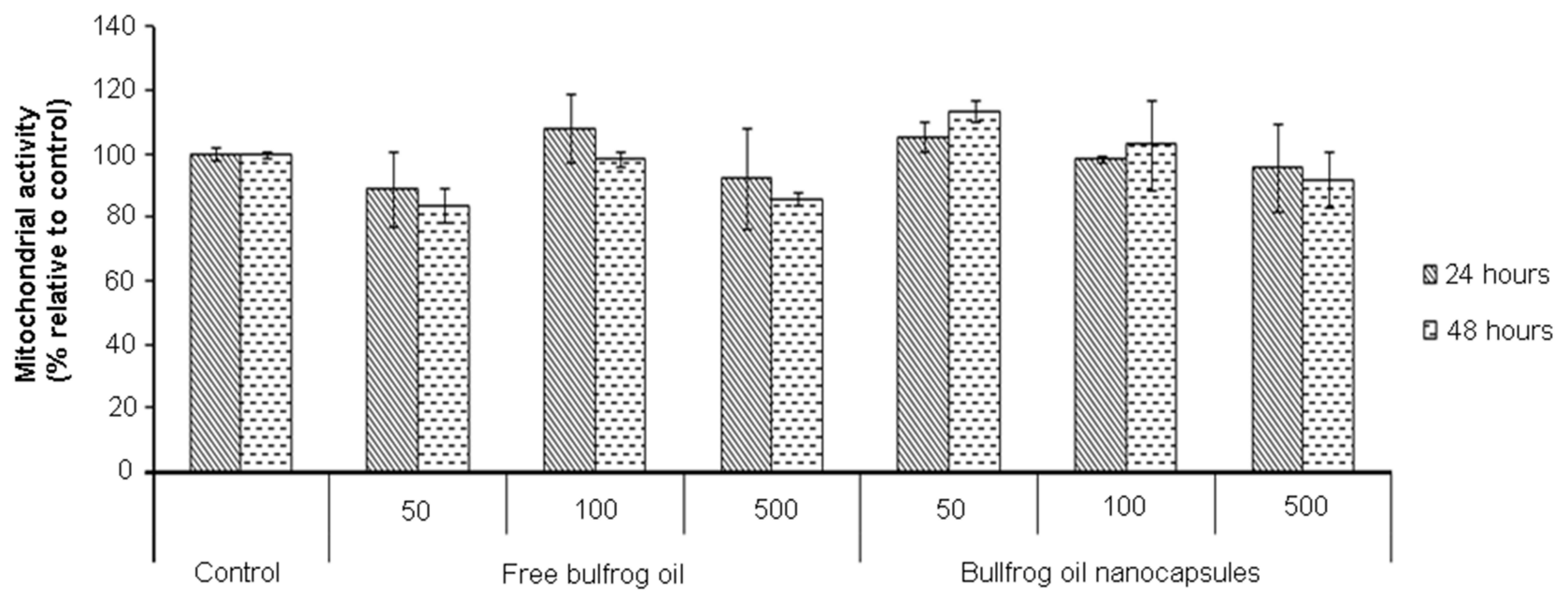

Bulfrog oil concentration $(\mu \mathrm{g} / \mathrm{mL})$

Figure 2 Mitochondrial activity (\%) of Raw 264.7 cells after 24 and 48 hours of treatment with free bullfrog oil and bullfrog oil nanocapsules at oil concentrations of 50 , 100 and $500 \mu \mathrm{g} \cdot \mathrm{mL}^{-.1}$.

microemulsions and nanoemulsions, did not show toxicity against healthy cells (RAW 264.7 cells, 3T3 healthy fibroblasts, and human erythrocytes). ${ }^{9,13,32}$

The biocompatibility of BFO can be attributed to its chemical composition. According to literature reports, PUFAs, isolated or even present in natural products, did not exert toxic effects on RAW 264.7 cells. ${ }^{33,34}$ In fact, Ambrozova et al isolated several PUFAs (ARA, EPA, and DHA) and revealed that they did not affect macrophages' cell viability and proliferation. The authors attributed this result to the absence of interference in ATP production in the cells. $^{33}$

Another study by Dias et al investigated the biocompatibility of PCL nanoparticles developed to carry a natural product rich in PUFAs. In their report, the nanoparticles did not reduce the mitochondrial activity of RAW 264.7 cells, as assessed by the MTT assay and optical microscopy. ${ }^{34}$ Hence, these reports indicate that the biocompatibility of BFO and BFONc is attributed to both the PUFAs in the BFO chemical composition and the PCL used.

Additionally, to evaluate the cell uptake of free BFO and BFONc and the morphological characteristics of RAW 264.7 cells after treatment, BFO was stained using Nile red dye. The micrographs obtained after cell treatment for 6,12 , and $24 \mathrm{~h}$ revealed that the controls (untreated cells) exhibited an intense nucleus blue fluorescence, which is ascribed to the Hoechst aqueous solution, a nucleus staining used as a contrast (Figure 3).
In addition, after $6 \mathrm{~h}$, the cells treated with free BFO showed red fluorescence in all cellular compartments, suggesting that the macrophages engulfed BFO. Nevertheless, the red fluorescence intensity decreased over $24 \mathrm{~h}$, implying that BFO was metabolized by the cells.

Interestingly, the cells treated with BFONc showed a completely different profile in the first $6 \mathrm{~h}$. Indeed, the oil fluorescence from this system was less intense than that from free BFO, although nuclear fluorescence was evident. The nanocapsule structure can explain these data, which is composed of an internal phase (BFO) surrounded by a polymeric layer. Such a structure may contribute to a delay in BFO release (depot effect), thereby preventing the interfacial tension between the BFO and the Hoechst staining aqueous solution, enabling nuclear fluorescence visualization in comparison to that with free BFO at $6 \mathrm{~h}$. Nonetheless, after 12 and $24 \mathrm{~h}$ of treatment, the micrographs showed high red fluorescence intensity compared with that at the first $6 \mathrm{~h}$, indicating that the nanocapsules released BFO.

Furthermore, it is essential to highlight that both free $\mathrm{BFO}$ and BFONc could not induce cell damage or morphological changes in RAW 264.7 cells even after being distributed to all cell compartments (membrane, cytoplasm, and nucleus). In addition to the MTT assay results signify that $\mathrm{BFO}$ and $\mathrm{BFONc}$ are safe and biocompatible against macrophage cells. As the developed nanostructured system exhibited favorable physicochemical and 


\section{Control}

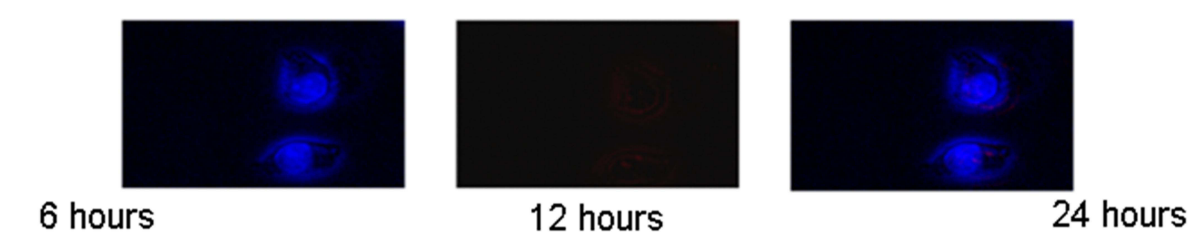

BFO
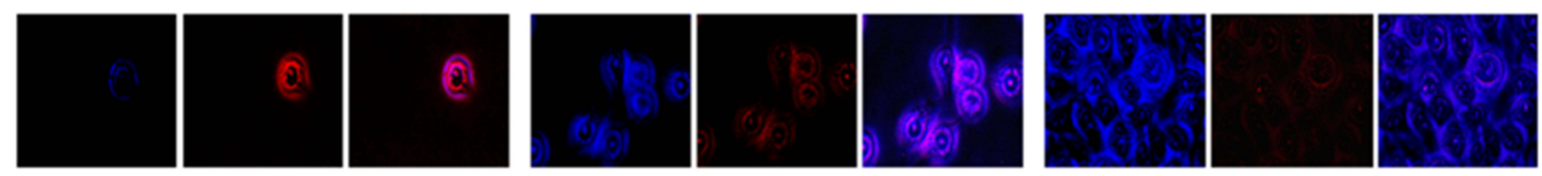

BFONc
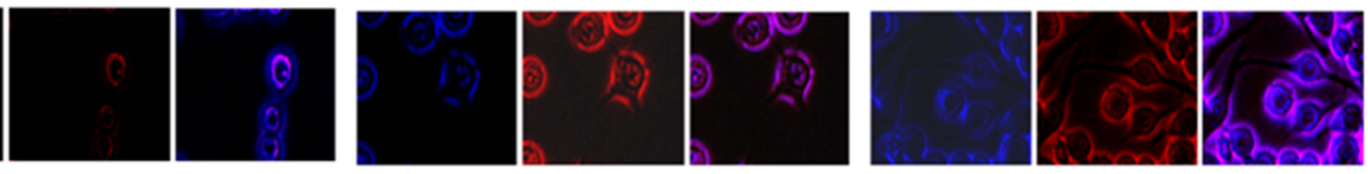

Figure 3 Micrographs obtained from fluorescence microscopy of Raw 264.7 cells after 6,12 and 24 hours of treatment with $100 \mu$ g.mL ${ }^{-1}$ of bullfrog oil. Control (untreated cells); BFO (free bullfrog oil); BFONc (bullfrog oil nanocapsules).

biocompatibility properties, the anti-inflammatory activities of both free BFO and BFONc were further evaluated by in vitro tests.

\section{Evaluation of Anti-Inflammatory Activity: In vitro Tests}

ROS are small and unstable molecules produced in cell mitochondria or by cytoplasmic enzymes, such as NADPH oxidase, cyclooxygenase, lipoxygenase, and xanthine oxidases, during anaerobic metabolism or via oxidation reactions. ${ }^{35}$ These molecules are involved in the cell differentiation and proliferation processes. However, they have unpaired electrons that are highly reactive to cell lipids and protein structures, leading to cellular damage. $^{35-37}$

In addition, ROS are related to the inflammatory process, as intracellular ROS production modulates the release of inflammatory mediators, such as cytokines, contributing to the inflammatory response. ${ }^{38}$ Therefore, quantification of ROS levels allows the evaluation of possible anti-inflammatory effects. The inflammatory process in murine macrophage cells (Raw 264.7) was stimulated using LPS. The intracellular ROS levels were evaluated after cell treatment with free BFO and BFONc for 24 and $48 \mathrm{~h}$ (Figure 4).

Overall, the results revealed that free BFO at all tested concentrations and times did not decrease ROS levels $(p>$ 0.05 ) compared to the control (untreated cells) (Figure 4). These findings may be related to oil consumption by the macrophages. In fact, in the cell uptake assay, the fluorescence intensity of $\mathrm{BFO}$ at $24 \mathrm{~h}$ was reduced compared to that at 6 and $12 \mathrm{~h}$, suggesting that BFO may be consumed by the cells. Therefore, as the ROS level was evaluated after 24 and $48 \mathrm{~h}$ of treatment with free BFO, the effect of BFO on ROS production was not observed. Nonetheless, BFONc showed a different profile of intracellular ROS levels. In the first $24 \mathrm{~h}$ of treatment, the BFONc system at 50 and $100 \mu \mathrm{g} \cdot \mathrm{mL}^{-1}$ of BFO concentration significantly $(p<0.05)$ decreased ROS levels of $-66 \pm 3 \%$ and $-44 \pm$ $3 \%$, respectively (Figure 4 ). These data evidenced the advantages of the nanostructured system. The use of BFONc improved the biological activity of the oil. This result is in agreement with that of Bernela et al. They developed bromelain-loaded katira gum nanoparticles and revealed, via in vivo studies, that delivery using nanoparticles enhanced the anti-inflammatory activity of these natural products. ${ }^{39}$ Additionally, the different behavior of BFONc compared to free BFO can be related to the depot effect caused by the nanostructured system, a phenomenon already discussed in the cell uptake assay.

In addition, BFONc at $500 \mu \mathrm{g} \cdot \mathrm{mL}^{-1}$ of BFO, after 24 h, showed a slight pro-inflammatory effect, increasing ROS levels by $30 \pm 9 \%$. Indeed, considering that BFO contains omega-3 and -6 PUFA series, ARA (the proinflammatory fatty acid with the highest lipophilicity and the lowest molecular weight among the components of BFO) may be the first one released and degraded by free radicals or cytoplasm enzymes. Moreover, at the lower 


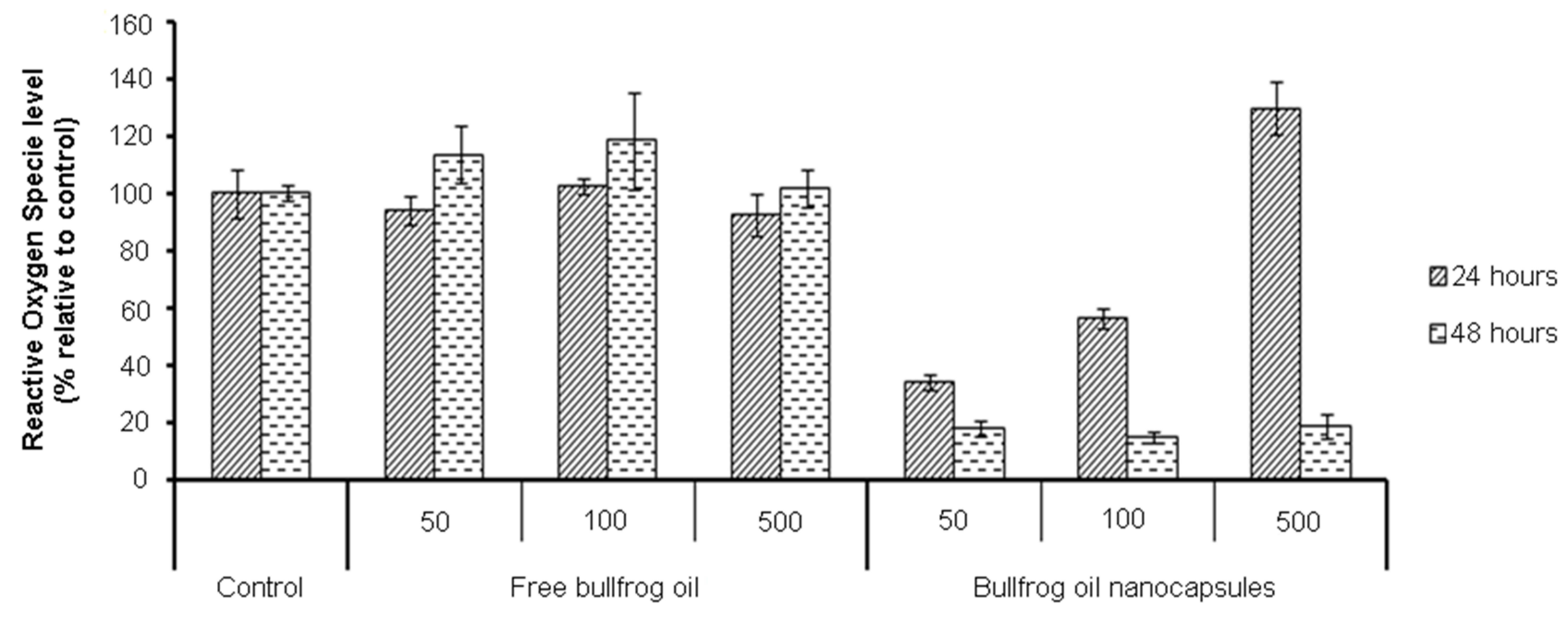

Bullfrog oil concentration $(\mu \mathrm{g} / \mathrm{mL})$

Figure 4 Intracellular reactive oxygen species (ROS) levels (\%) on Raw 264.7 cells stimulated for 12 hours with lipopolysaccharide (LPS) after 24 and 48 hours of treatment with free bullfrog oil and bullfrog oil nanocapsules at the concentration of 50,100 and $500 \mu \mathrm{g} / \mathrm{mL}$.

concentrations tested (50 and $\left.100 \mu \mathrm{g} \cdot \mathrm{mL}^{-1}\right)$, the ARA concentration might not be sufficient to induce proinflammatory activity. Although supported by the literature, this hypothesis was not tested because the BFONc was tested in an aqueous medium. In such media, assessing the fatty acid release profile by gas chromatography was not possible since this technique does not allow the use of samples with water content.

On the contrary, after $48 \mathrm{~h}$ of treatment, BFONc at all tested concentrations significantly $(p<0.05)$ decreased ROS levels by at least $81 \pm 4 \%$. These data show the ability of BFONc to reduce ROS levels, suggesting that this nanostructured system improves the activity of free BFO in vitro. Therefore, BFONc appears to be a nanosystem with potential anti-inflammatory activity.

ROS levels can be associated with NO production. Inflammatory mediators are produced during the respiratory macrophage process, which is burst by the enzymatic reactions promoted by NADPH oxidase and NO synthase during the inflammatory process. ${ }^{40}$ Therefore, the NO level of RAW 264.7 cells was also evaluated following stimulation with LPS and treatment with free BFO and BFONc for 24 and $48 \mathrm{~h}$ (Figure 5).

After $24 \mathrm{~h}$ of treatment with free BFO at all tested concentrations, although there was a marked reduction in $\mathrm{NO}$ levels compared to those in untreated cells, the decrease was not significant $(p<0.05)$ (Figure 5). Nonetheless, free BFO did reduce the NO level up to $29 \pm 7 \%$, demonstrating its suitability for attenuating NO production at different concentrations. In addition, at $48 \mathrm{~h}$, the NO levels remained unchanged from that at $24 \mathrm{~h}$, revealing that free BFO did decrease NO levels in a concentration-dependent manner. Similar results were reported by Barbosa et al, who showed that a combination of BFO and $\mathrm{Cetiol}^{\circledR} \mathrm{V}$ diminished NO level by approximately 30\% in LPS-stimulated RAW 264.7 cells after $48 \mathrm{~h} .{ }^{12}$ However, this author used a marketable BFO sample with an unknown production process. In contrast, in this work, BFO was obtained via hot extraction as proposed by Amaral-Machado, which ensures the reproducibility of the chemical characteristics of the oil. ${ }^{9}$

Moreover, these results are in contrast with the ROS level data. Indeed, free BFO did not alleviate ROS levels, but it significantly decreased NO production. This can be ascribed to the regulatory effect of PUFA, which was present in BFO, on ROS and NO production by LPSstimulated macrophages. This rationale was corroborated by the results reported by Ambrozova et al, who verified that only at higher concentrations $(100 \mu \mathrm{M})$ did isolate PUFAs (EPA, linoleic acid, and $\alpha$-linoleic acid) decrease ROS production. Additionally, the PUFAs exhibited a remarkable inhibitory effect on NO. ${ }^{33}$ Although the effect of PUFAs on ROS and NO production has not been fully elucidated, the BFO activity observed in the present study is in agreement with previous findings. ${ }^{33}$

Additionally, BFONc at 50 and $100 \mu \mathrm{g} \cdot \mathrm{mL}^{-1}$, after $24 \mathrm{~h}$ of treatment, decreased NO levels by approximately 


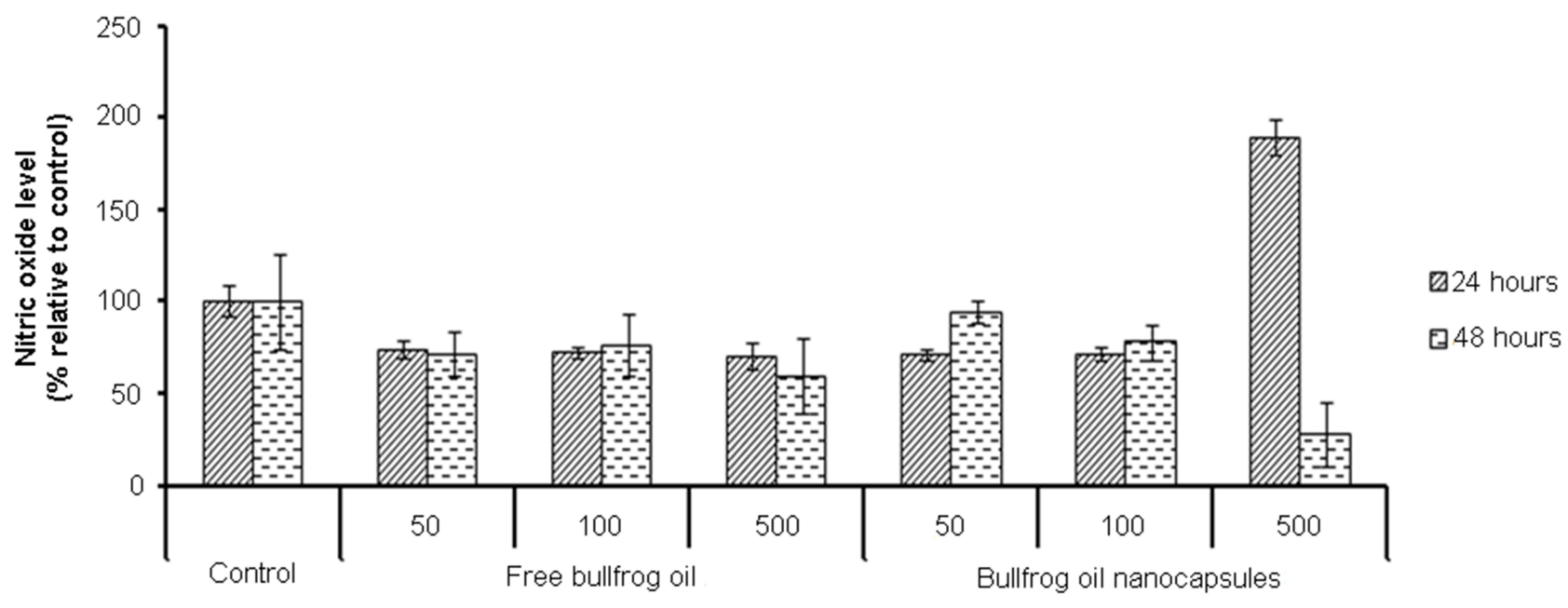

Bullfrog oil concentration ( $\left.\mu \mathrm{g} \cdot \mathrm{ml}^{-1}\right)$

Figure 5 Nitric oxide (NO) levels (\%) of Raw 264.7 cells stimulated for 12 hours with lipopolysaccharide (LPS) and treated after 24 and 48 hours with free bullfrog oil and bullfrog oil nanocapsules at concentrations of 50,100 and $500 \mu \mathrm{g} \cdot \mathrm{mL}^{-.}$.

$30 \%$, similar to free BFO. However, at an oil concentration of $500 \mu \mathrm{g} . \mathrm{mL}-1$, the same system showed a pro-inflammatory activity, based on the high NO dosage of approximately $180 \%$. These data were in complete agreement with those from the dosage of ROS. Indeed, BFONc at $500 \mu \mathrm{g} . \mathrm{mL}^{-1}$ also increased ROS production by cells after $24 \mathrm{~h}$ of treatment. Therefore, BFONc may stimulate the activation of NADPH oxidase or NO synthase enzymes, contributing to the increase in NO production. ${ }^{41,42}$

It is noteworthy that the effect of BFONc on the reduction of NO levels at $48 \mathrm{~h}$ of treatment was not observed for the systems containing an oil concentration of $50 \mu \mathrm{g} \cdot \mathrm{mL}^{-1}(6 \pm 6 \%)$. However, the samples at 100 and $500 \mu \mathrm{g} . \mathrm{mL}^{-1}$ of oil concentration decreased NO level by $22 \pm 10 \%$ and $72 \pm 18 \%$, respectively. These samples highlight the potential of this nanostructured system to enhance the in vitro anti-inflammatory activity of BFO.

Overall, these data suggest the potential antiinflammatory activity of BFO and that the efficacy of this oil in inhibiting both ROS and NO production is improved by nanoencapsulation.

\section{Determination of the Cytokines (Type-6 Interleukin (IL-6) and Tumor Necrosis Factor (TNF) Levels}

Based on the ability of free BFO and BFONc to decrease ROS and NO production, and because these molecules are involved in the modulation of release of inflammatory mediators, such as cytokines, the in vitro anti- inflammatory activity of free BFO and BFONc was also assessed by measuring pro-inflammatory cytokine (IL-6 and TNF) levels.

Figure 6 shows the levels of TNF and IL-6 after in vitro treatment with free BFO and BFONc for 48 h. All tested concentrations showed slightly reduced TNF levels (by approximately 10\%) in both free BFO and BFONc. This result is consistent with that of Barbosa et al, who attributed the BFO-induced decrease in TNF levels to the biological activities of n-3 PUFAs. These fatty acids can modulate the anti-inflammatory response and diminish TNF release. ${ }^{12,43}$ These results support the initial hypothesis that the chemical composition of BFO is responsible for its anti-inflammatory effect.

Additionally, measurement of IL-6 levels after treatment with free BFO showed that only the highest tested concentration (500 $\left.\mu \mathrm{g} . \mathrm{mL}^{-1}\right)$ effectively decreased the level of this pro-inflammatory cytokine $(12 \pm 8 \%)$. This finding is also in agreement with that of Barbosa et al, who observed that BFO decreased IL-6 levels only at a concentration of $200 \mu \mathrm{g} \cdot \mathrm{mL}^{-1} \cdot{ }^{12}$

In contrast, BFONc was much more effective in reducing IL-6 levels. As shown in Figure 6, BFO nanoencapsulation at 50,100 , and $500 \mu \mathrm{g} \cdot \mathrm{mL}^{-1}$ concentrations resulted in decreases of $51 \pm 14 \%, 44 \pm 8 \%$, and $89 \pm$ $14 \%$ in the levels of this cytokine, respectively $(p<0.05)$. These results can be ascribed to both the effective delivery of BFO by the nanostructured system and the chemical composition of BFO itself, mainly n-3 PUFAs (EPA and 


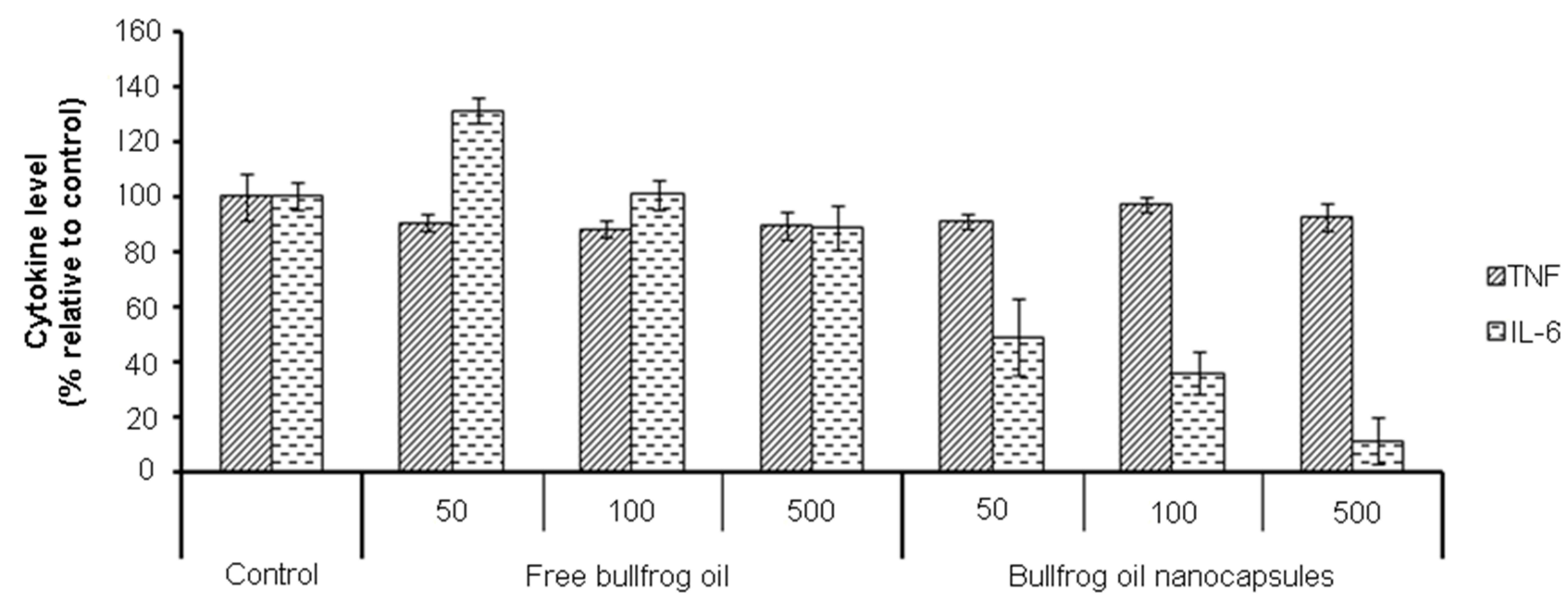

Bullfrog oil concentration ( $\left.\mu \mathrm{g} \cdot \mathrm{ml}^{-1}\right)$

Figure 6 TNF and IL-6 levels (\%) of Raw 264.7 stimulated for 12 hours with lipopolysaccharide (LPS) after 48 hours of treatment with free bullfrog oil and bullfrog oil nanocapsules at the concentrations of 50,100 and $500 \mu \mathrm{g} \cdot \mathrm{mL}^{-.1}$.

DHA), which represent $18.4 \%$ of the total $24.8 \%$ of the BFO PUFAs series. ${ }^{9,11}$

\section{Preclinical Trials of the Anti-Inflammatory Activity}

The anti-edematogenic effect of pre-treatment with BFO and BFONc was evaluated in a carrageenan-induced paw edema model. As expected, the carrageenan edemainduced animals treated with saline (negative control) presented signs of severe inflammation, such as edema formation, hyperalgesia, and erythema, at all tested times $(1,2,3$, and $4 \mathrm{~h})$. On the contrary, the mice treated with BFO $(50,100$, and $500 \mathrm{mg} / \mathrm{kg})$ showed a significant reduction $(p<0.05)$ in edema formation after $2 \mathrm{~h}$ of inflammation induction $(44 \pm 10 \%, 40 \pm 17 \%$, and $34 \pm 9 \%$ of total edema, respectively) in a time-dependent manner compared to the negative control (Figure 7A). Similarly, BFONc at $500 \mathrm{mg} / \mathrm{kg}$ exhibited anti-inflammatory activity after $2 \mathrm{~h}$ of inflammation stimulation $(41 \pm 15 \%$ of total edema). In contrast, BFONc at 50 and $100 \mathrm{mg} / \mathrm{kg}$ displayed anti-inflammatory effects $(52 \pm 18 \%$ and $62 \pm$ $18 \%$ of total edema, respectively) only after $3 \mathrm{~h}$ (Figure 7C). Moreover, both BFO and BFONc exerted remarkable anti-inflammatory effects at $500 \mathrm{mg} / \mathrm{kg}$, leading to a reduction of edema formation by $56 \pm 2 \%$ and 54 $\pm 1 \%$, respectively.

Additionally, considering the total edema effect, as calculated by the area under the time-course curves after
$4 \mathrm{~h} \quad\left(\mathrm{AUC}_{0-4 \mathrm{~h}}\right)$, free $\mathrm{BFO}$ showed effective antiinflammatory effects at all evaluated doses (Figure 7B). In comparison, BFONc exhibited the most potent antiinflammatory effect at the highest dose $(500 \mathrm{mg} / \mathrm{kg})(p<$ 0.001 ) (Figure 7D). In addition, it is important to highlight the effectiveness of BFONc at other tested concentrations, as they displayed a significant difference $(p<0.05)$.

Indeed, these results of the anti-inflammatory potential of free BFO and BFONc agree with those of Barbosa et al, who showed that BFO could decrease paw edema by up to $50 \%$ in rats and corroborate the findings of the in vitro assay. ${ }^{12}$ Furthermore, the lowest efficacy of BFONc at 50 and $100 \mathrm{mg} / \mathrm{kg}$, compared to BFONc at $500 \mathrm{mg} / \mathrm{kg}$, can be explained by the properties of the nanostructured system itself. As already discussed, the nanocapsules may act as reservoir systems. They must progressively release the oil via polymer relaxation mechanisms, allowing the diffusion of BFO from the nanocapsules polymeric shell. Therefore, the delivered concentration of the oil was not sufficient to exert the potent effect shown by BFONc at $500 \mathrm{mg} / \mathrm{kg} .{ }^{15,26}$

Regarding MPO quantification, the mice administered with different doses of $\mathrm{BFO}(50,100$, and $500 \mathrm{mg} / \mathrm{kg}$ ) (Figure 8A) and BFONc (50, 100, and $500 \mathrm{mg} / \mathrm{kg}$ ) (Figure $8 \mathrm{~B}$ ) via intragastric gavage showed a significant reduction $(p<0.05)$ in MPO levels compared to the negative control (Figure 8).

The association between carrageenan-induced paw edema and MPO levels can be a promising approach to 

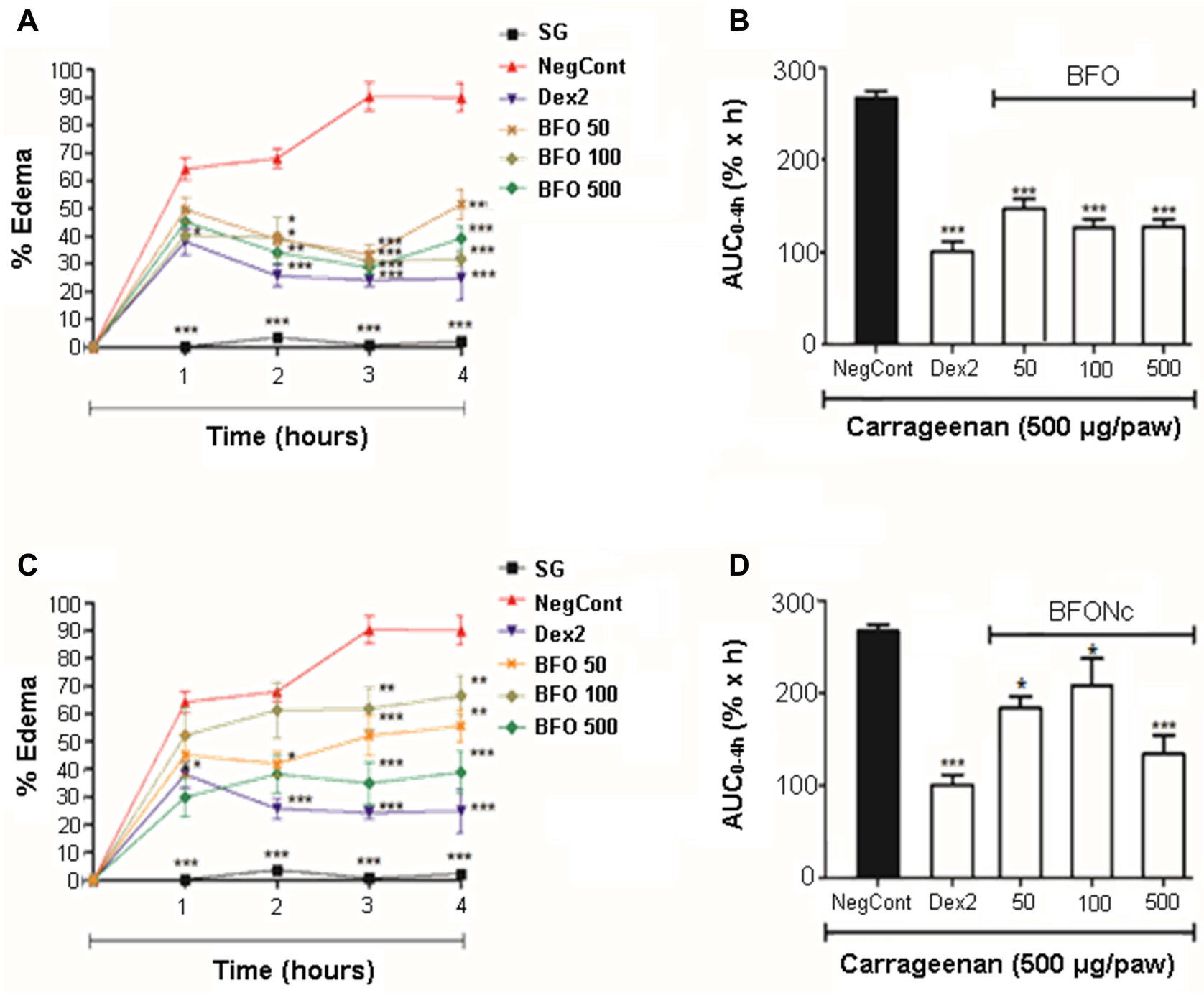

Figure 7 Anti-edematogenic effect of the pre-treatment with free bullfrog oil (BFO) and bullfrog oil nanocapsules (BFONc) at 50,100 or $500 \mathrm{mg} / \mathrm{kg}$ in carrageenan-induced paw edema model. (A) Percentage of edema and (B) area under the curve (AUC) for the percentage of paw edema as a function of time ( $0-4 \mathrm{~h}$ ) in mice treated with the BFO; (C) percentage of edema and (D) AUC for the percentage of paw edema as a function of time $(0-4 \mathrm{~h})$ in mice treated with the BFONc. $* * * p<0.00 \mathrm{I}$, $* * p<0.0 \mathrm{I}$, and $*_{p}<0.05$ compared to the group treated with saline (negative control). Data showed as mean $\pm \operatorname{SEM}(n=6)$.

Abbreviations: SG, sham group; NegCont, negative control; Dex 2, dexamethasone $(2.0 \mathrm{mg} / \mathrm{kg})$; BFO 50 , bullfrog oil at $50 \mathrm{mg} / \mathrm{kg}$; BFO 100 , bullfrog oil at $100 \mathrm{mg} / \mathrm{kg}$; BFO 500 , bullfrog oil at $500 \mathrm{mg} / \mathrm{kg}$; BFONc 50 , bullfrog oil nanocapsules at $50 \mathrm{mg} / \mathrm{kg}$; BFONc 100 , bullfrog oil nanocapsules at $100 \mathrm{mg} / \mathrm{kg}$; BFONc 500 , bullfrog oil nanocapsules at $500 \mathrm{mg} / \mathrm{kg}$.

evaluate the inflammatory activity of compounds by in vivo experiments. Within the first $2 \mathrm{~h}$ after induction, edema formation is led by releasing histamine, serotonin, and bradykinin, following increased vascular permeation. Subsequently, inflammatory cell recruitment (especially neutrophils and monocytes) is activated, and their degranulation promotes the release of inflammatory markers/ mediators, among which MPO is emphasized. ${ }^{20,22,44,45}$

Indeed, MPO release induces several free radicals, which trigger oxidative stress in cells, leading to tissue injury. Therefore, inhibition of MPO release is directly related to the anti-inflammatory effect, as demonstrated by Rudolph et al and De La Rebière et al, who showed that the binding of MPO may explain the antiinflammatory effect of heparin to endothelial cells and glycosaminoglycans. ${ }^{46,47}$

In general, the findings from the in vitro and in vivo studies suggest that BFONc effectively delivers BFO and reduces the levels of the primary biological mediators related to the inflammation process. As evidenced in the present study, polymeric nanocapsules have exhibited remarkable efficiency in increasing the anti-inflammatory activity of drugs and natural compounds. This phenomenon can be corroborated by the mesalazine/ 
A

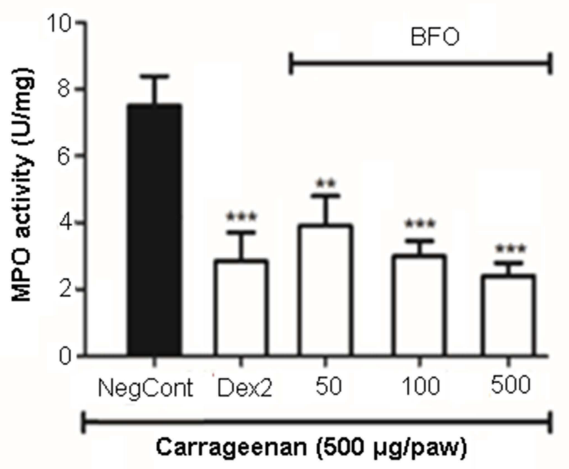

B

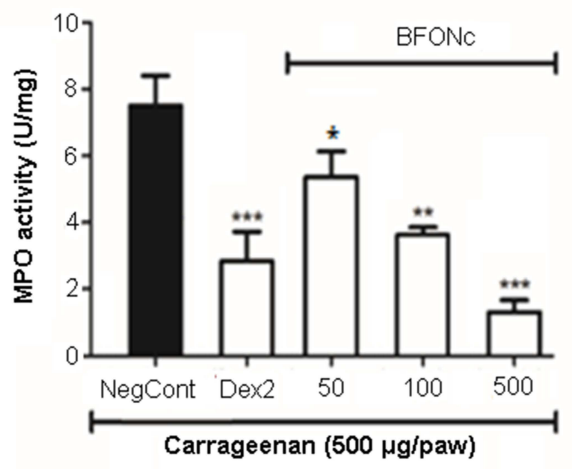

Figure 8 Effect of free bullfrog oil (BFO) and bullfrog oil nanocapsules (BFONc) on the myeloperoxidase (MPO) activity in carrageenan-induced paw edema model. (A) MPO activity of BFO and (B) MPO activity of BFONc at 50,100 or $500 \mathrm{mg} / \mathrm{kg}$. $* * * p<0.00 \mathrm{I}, * * p<0.01$ and $* p<0.05$ compared to the negative control (NegCont). Data showed as mean $\pm \operatorname{SEM}(n=6)$.

hydroxypropyl- $\beta$-cyclodextrin chitosan-coated nanoparticles developed by Tang et al. The nanoencapsulation process allowed sustained drug release, decreasing the levels of NO, PGE2, and IL-8 in stimulated HepG2 cells. ${ }^{48}$ Similar findings were also observed for $\alpha$-bisabolol PCL nanoparticles, which showed meaningful activity in acute lung inflammation model. ${ }^{49}$

Based on these remarks, the overall results of this study confirm the anti-inflammatory effect of BFO. Both the in natura oil composition and the physicochemical characteristics of the developed nanostructured system lead to a remarkable reduction in the inflammatory edema process and the levels of inflammatory mediators, such as MPO. Therefore, BFONc has been shown as a biocompatible system capable of maintaining the anti-inflammatory activity of $\mathrm{BFO}$ and overcoming the mentioned disadvantages of the oil, thereby allowing its enteral administration.

\section{Conclusions}

Overall, the results presented here show the formation of BFO-based nanocapsules with suitable physicochemical and morphological characteristics. These findings allow us to predict their use as stable and promising therapeutic products and their storage properties at room temperature, facilitating its management until administration. The absence of interference on the mitochondrial activity and morphology of Raw 264.7 murine macrophage cells after treatment with BFONc evidenced that this nanostructured system has suitable in vitro biocompatibility, which is an important parameter in preclinical trials that suggests system safety. The ability of BFO to decrease the levels of inflammatory mediators was revealed by in vitro anti- inflammatory tests and reinforced by the in vivo experiments, which showed the remarkable anti-inflammatory activity of both $\mathrm{BFO}$ and $\mathrm{BFONc}$ via reduction of paw edema and MPO levels in mice. Taken together, these preclinical data support the successful development of BFO-based nanocapsules with relevant in vitro and in vivo biological effects against inflammatory processes and open new directions for future studies using BFO, prompting further investigation of the anti-inflammatory activity of BFONc in clinical trials.

\section{Abbreviations}

DCFH-DA, 2', 7'-dichlorofluorescein diacetate; ATP, adenosine triphosphate; ARA, arachidonic acid; AUC, area under the curve; BFO, bullfrog oil; BFONc, bullfrog oil nanocapsules; DMSO, dimethyl sulfoxide; DHA, docosahexaenoic acid; DMEM, Dulbecco's Modified Eagle Medium; DLS, dynamic light scattering; EPA, eicosapentaenoic acid; FBS, fetal bovine serum; FDA, Food Drug Administration; LPS, lipopolysaccharide; MTT, 3-(4, (5-dimethylthiazol-2-yl)-2,5-diphenyltetrazolium bromide; MPO, myeloperoxidase; NO, nitric oxide; PBS, phosphate buffer standard; PCL, polycaprolactone; PdI, polydispersity index; PUFAS, polyunsaturated fatty acids; ROS, reactive oxygen species; $\mathrm{SD}$, standard deviation; TEM, transmission electron microscopy; TNF, tumor necrosis factor; IL-6, type-6 interleukin.

\section{Acknowledgment}

This work was supported by to the Coordenação de Aperfeiçoamento de Pessoal de Nível superior - Brazil (CAPES) - Finance code 001. The authors thank to the 
Coordenação de Aperfeiçoamento de Pessoal de Nível superior - Brazil (CAPES) and Conselho Nacional de Desenvolvimento Científico e Tecnológico (CNPQ).

\section{Disclosure}

The authors report no conflicts of interest in this work.

\section{References}

1. Wiktorowska-Owczarek A, Berezinska M, Nowak JZ. PUFAs: structures, metabolism and functions. Adv Clin Exp Med. 2015;24 (6):931-941. doi:10.17219/acem/31243

2. Zárate R, el Jaber-Vazdekis N, Tejera N, Pérez JA, Rodríguez C. Significance of long chain polyunsaturated fatty acids in human health. Clin Transl Med. 2017;6(1):25. doi:10.1186/s40169-0170153-6

3. Calder PC. Omega-3 polyunsaturated fatty acids and inflammatory processes: nutrition or pharmacology? Br J Clin Pharmacol. 2013;75 (3):645-662. doi:10.1111/j.1365-2125.2012.04374.x

4. Calder PC. Omega-3 fatty acids and inflammatory processes: from molecules to man. Biochem Soc Trans. 2017;45(5):1105-1115. doi:10.1042/BST20160474

5. Ratledge C, Wynn JP. The biochemistry and molecular biology of lipid accumulation in oleaginous microorganisms. Adv Appl Microbiol. 2002;51:1-52.

6. Fernando IS, Nah J-W, Jeon Y-J. Potential anti-inflammatory natural products from marine algae. Environ Toxicol Pharmacol. 2016;48: 22-30. doi:10.1016/j.etap.2016.09.023

7. Suleria H, Osborne S, Masci P, Gobe G. Marine-based nutraceuticals: an innovative trend in the food and supplement industries. Mar Drugs. 2015;13(10):6336-6351. doi:10.3390/md13106336

8. Davim ALS, Dantas TNC, Albuquerque DF, Pereira MR, Queiroz LBTS, Freitas LM. Anti-inflammatory potential of microemulsion and pure bullfrog oil in muscle injury. Rev Bras Med Esp. 2017;23(3):237-240. doi:10.1590/1517-869220172303159519

9. Amaral-Machado L, Xavier-Junior FH, Rutckeviski R, et al. New trends on antineoplastic therapy research: bullfrog (Rana catesbeiana Shaw) oil nanostructured systems. Molecules. 2016;21(5):585. doi: $10.3390 /$ molecules 21050585

10. Méndez E, Sanhueza J, Nieto S, Speisky H, Valenzuela A. Fatty acid composition, extraction, fractionation, and stabilization of bullfrog (Rana catesbeiana) oil. J Am Oil Chem Soc. 1998;75(1):67-71. doi:10.1007/s11746-998-0012-0

11. Rutckeviski R, Xavier-Junior FH, Morais AR, et al. Thermooxidative stability evaluation of bullfrog (Rana catesbeiana Shaw) oil. Molecules. 2017;22(4):606. doi:10.3390/molecules22040606

12. Barbosa LMQ, Amaral-Machado L, Félix-Silva J, et al. Bullfrog oil reduces the carrageenan-induced edema in Wistar rats by in vitro reduction of inflammatory mediators. J Oleo Sci. 2020;69(2):13 3-142. doi:10.5650/jos.ess 19215

13. Moreira-Oliveira SS, Amaral-Machado L, de Oliveira WN, et al. Buccal bullfrog (Rana catesbeiana Shaw) oil emulsion: a mucoadhesive system intended for treatment of oral candidiasis. Pharmaceutics. 2018;10(4):257. doi:10.3390/pharmaceutics10040 257

14. Oliveira WN, Amaral-Machado L, Alencar EN, et al. Getting the jump on the development of bullfrog oil microemulsions: a nanocarrier for Amphotericin B intended for antifungal treatment. AAPS PharmSciTech. 2018;19(6):2585-2597. doi:10.1208/s12249018-1093-1

15. Abriata JP, Turatti RC, Luiz MT, et al. Development, characterization and biological in vitro assays of paclitaxel-loaded PCL polymeric nanoparticles. Mater Sci Eng C. 2019;96:347-355. doi:10.1016/j. msec.2018.11.035
16. Liu J, Xu L, Liu C, et al. Preparation and characterization of cationic curcumin nanoparticles for improvement of cellular uptake. Carbohydr Polym. 2012;90(1):16-22. doi:10.1016/j.carbpol.2012. 04.036

17. Sipponen MH, Henn A, Penttilä P, Österberg M. Lignin-fatty acid hybrid nanocapsules for scalable thermal energy storage in phase-change materials. Chem Eng J. 2020;393(1):124711. doi:10.1016/j.cej.2020.124711

18. Zanetti M, Mazon LR, Meneses AC, et al. Encapsulation of geranyl cinnamate in polycaprolactone nanoparticles. Mater Sci Eng C. 2019;97:198-207. doi:10.1016/j.msec.2018.12.005

19. Fessi H, Puisieux F, Devissaguet JP, Ammoury N, Benita S. Nanocapsule formation by interfacial polymer deposition following solvent displacement. Int J Pharm. 1989;55(1):R1-R4. doi:10.1016/ 0378-5173(89)90281-0

20. Winter CA, Risley EA, Nuss GW. Carrageenin-induced edema in hind paw of the rat as an assay for anti-inflammatory drugs. Exp Biol Med. 1962;111(3):544-547. doi:10.3181/00379727-111-27849

21. Bradley PP, Priebat DA, Christensen RD, Rothstein G. Measurement of cutaneous inflammation: estimation of neutrophil content with an enzyme marker. J Invest Dermatol. 1982;78:206-209. doi:10.1111/ 1523-1747.ep12506462

22. Posadas I, Bucci M, Roviezzo F, et al. Carrageenan-induced mouse paw oedema is biphasic, age-weight dependent and displays differential nitric oxide cyclooxygenase-2 expression. Br J Pharmacol. 2004;142(2):331-338. doi:10.1038/sj.bjp.0705650

23. Enayati M, Ahmad Z, Stride E, Edirisinghe M. Size mapping of electric field-assisted production of polycaprolactone particles. $J$ R Soc Interface. 2010;suppl_4(7):S393-S402.

24. Schaffazick SR, Guterres SS, Freitas LLL, Pohlmann AR. Caracterização e estabilidade físico-química de sistemas poliméricos nanoparticulados para administração de fármacos. Quim Nova. 2003;26(5):726-737. doi:10.1590/S0100-40422003000500017

25. Goycoolea FM, Valle-Gallego A, Stefani R, et al. Chitosan-based nanocapsules: physical characterization, stability in biological media and capsaicin encapsulation. Colloid Polymer Sci. 2012;290 (14):1423-1434. doi:10.1007/s00396-012-2669-z

26. Byun Y, Hwang JB, Bang SH, et al. Formulation and characterization of $\alpha$-tocopherol loaded poly $\varepsilon$-caprolactone (PCL) nanoparticles. LWT. 2011;44(1):24-28. doi:10.1016/j.lwt.2010.06.032

27. Rafiei P, Haddadi A. Docetaxel-loaded PLGA and PLGA-PEG nanoparticles for intravenous application: pharmacokinetics and biodistribution profile. Int J Nanomed. 2017;12(1):935. doi:10.2147/IJN. S121881

28. Calvo P, Vila-Jato JL, Alonso MJ. Comparative in vitro evaluation of several colloidal systems, nanoparticles, nanocapsules, and nanoemulsions, as ocular drug carriers. J Pharm Sci. 1996;85(5):530-536.

29. Lacoulonche F, Gamisans F, Chauvet A, Garcia ML, Espina M, Egea MA. Stability and in vitro drug release of flurbiprofen-loaded poly-e-caprolactone nanospheres. Drug Dev Ind Pharm. 1999;25 (9):983-993. doi:10.1081/DDC-100102261

30. Lambert G, Fattal E, Pinto-Alphandary H, Gulik A, Couvreur P. Polyisobutylcyanoacrylate nanocapsules containing an aqueous core as a novel colloidal carrier for the delivery of oligonucleotides. Pharm Res. 2000;17(6):707-714. doi:10.1023/A:1007582332491

31. International Organization for Standardization (ISO). Biological Evaluation of Medical Devices. Part 5: Tests for in vitro Cytotoxicity. Geneva: Switzerland; 2009:10993-10995.

32. Bonatto CC, Joanitti GA, Silva LP. In vitro cytotoxic activity of chitosan-bullfrog oil microemulsion against melanoma cells. IET Nanobiotechnol. 2015;9(4):172-177. doi:10.1049/iet-nbt.2014. 0010

33. Ambrozova G, Pekarova M, Lojek A. Effect of polyunsaturated fatty acids on the reactive oxygen and nitrogen species production by raw 264.7 macrophages. Eur J Nutr. 2010;49(3):133-139. doi:10.1007/ s00394-009-0057-3 
34. Dias AMA, Rey-Rico A, Oliveira RA, et al. Wound dressings loaded with an anti-inflammatory jucá (Libidibia ferrea) extract using supercritical carbon dioxide technology. J Supercrit Fluids. 2013;74 34-45. doi:10.1016/j.supflu.2012.12.007

35. Cadenas S. Mitochondrial uncoupling, ROS generation and cardioprotection. Biochim Biophys Acta Bioenerg. 2018;1859 (9):950. doi:10.1016/j.bbabio.2018.05.019

36. Moloney JN, Cotter TG. ROS signalling in the biology of cancer Semin Cell Dev Biol. 2018;80:50-64.

37. Redza-Dutordoir M, Averill-Bates DA. Activation of apoptosis signalling pathways by reactive oxygen species. Biochim Biophys Acta. 2016;1863(12):2977-2992. doi:10.1016/j.bbamcr.2016.09. 012

38. Liu X, Du H, Chen D, et al. Cyclophilin D deficiency protects against the development of mitochondrial ROS and cellular inflammation in aorta. Biochem Biophys Res Commun. 2019;508(4):1202-1208. doi:10.1016/j.bbrc.2018.12.064

39. Bernela M, Ahuja M, Thakur R. Enhancement of anti-inflammatory activity of bromelain by its encapsulation in katira gum nanoparticles. Carbohydr Polym. 2016;143(1):18-24. doi:10.1016/j.carbpol.2016. 01.055

40. Rendra E, Riabov V, Mossel DM, Sevastyanova T, Harmsen MC, Kzhyshkowska J. Reactive oxygen species (ROS) in macrophage activation and function in diabetes. Immunobiology. 2019;224 (2):242-253. doi:10.1016/j.imbio.2018.11.010

41. Galinari E, Almeida-Lima J, Macedo GR, Mantovani HC, Rocha HAO. Antioxidant, antiproliferative, and immunostimulatory effects of cell wall alpha-d-mannan fractions from Kluyveromyces marxianus. Int J Biol Macromol. 2018;109:837-846. doi:10.1016/j. ijbiomac.2017.11.053
42. Tung YT, Chua MT, Wang SY, Chang ST. Anti-inflammation activities of essential oil and its constituents from indigenous cinnamon (Cinnamomum osmophloeum) twigs. Bioresour Technol. 2008;99 (9):3908-3913. doi:10.1016/j.biortech.2007.07.050

43. Zhao G, Etherton TD, Martin KR, et al. Anti-inflammatory effects of polyunsaturated fatty acids in THP-1 cells. Biochem Biophys Res Commun. 2005;336(3):909-917. doi:10.1016/j.bbrc.2005.08.204

44. Ndrepepa G. Myeloperoxidase-A bridge linking inflammation and oxidative stress with cardiovascular disease. Clin Chim Acta. 2019;493:36-51. doi:10.1016/j.cca.2019.02.022

45. Vinegar R, Schreiber W, Hugo R. Biphasic development of carrageenin edema in rats. J Pharmacol Exp Ther. 1969;166(1):96-103.

46. De la Rebière G, Franck T, Deby-Dupont G, et al. Effects of unfractionated and fractionated heparins on myeloperoxidase activity and interactions with endothelial cells: possible effects on the pathophysiology of equine laminitis. Vet J. 2008;178(1):62-69. doi:10.1016/j. tvj1.2007.08.033

47. Rudolph V, Heitzer T, Roiss M, Rudolph T, Meinertz T, Baldus S. Heparins increase endothelial nitric oxide bioavailability by liberating vessel-immobilized myeloperoxidase. J Thorac Cardiovasc Surg. 2007;55(S1):MP 68. doi:10.1055/s-2007-967424

48. Tang P, Sun Q, Zhao L, et al. Mesalazine/hydroxypropyl- $\beta$ cyclodextrin/chitosan nanoparticles with sustained release and enhanced anti-inflammation activity. Carbohydr Polym. 2018;198 (1):418-425. doi:10.1016/j.carbpol.2018.06.106

49. D'Almeida APL, Oliveira MTP, Souza ET, et al. $\alpha$-bisabolol-loaded lipid-core nanocapsules reduce lipopolysaccharide-induced pulmonary inflammation in mice. Int $J$ Nanomed. 2017;12(1):4479. doi:10.2147/IJN.S130798
International Journal of Nanomedicine

\section{Publish your work in this journal}

The International Journal of Nanomedicine is an international, peerreviewed journal focusing on the application of nanotechnology in diagnostics, therapeutics, and drug delivery systems throughout the biomedical field. This journal is indexed on PubMed Central, MedLine, CAS, SciSearch ${ }^{\circledR}$, Current Contents ${ }^{\circledR} /$ Clinical Medicine,
Journal Citation Reports/Science Edition, EMBase, Scopus and the Elsevier Bibliographic databases. The manuscript management system is completely online and includes a very quick and fair peer-review system, which is all easy to use. Visit http://www.dovepress.com/ testimonials.php to read real quotes from published authors. 